\title{
Removal of Di-2-Ethyl Hexyl Phthalates by Membrane Bioreactor
}

\author{
Salah Al Sakiti ${ }^{1}$, Suwanna Kitpati Boontanon ${ }^{1 *}$, Narin Boontanon ${ }^{2}$ \\ ${ }^{1}$ Civil and Environmental Engineering Department, Faculty of Engineering, Mahidol University, Salaya, Thailand; ${ }^{2}$ Faculty of Envi- \\ ronment and Resource Studies, Mahidol University, Salaya, Thailand. \\ Email: "suwanna.boo@mahidol.ac.th
}

Received December $18^{\text {th }}, 2012$; revised February $24^{\text {th }}, 2013$; accepted March $27^{\text {th }}, 2013$

Copyright (C) 2013 Salah Al Sakiti et al. This is an open access article distributed under the Creative Commons Attribution License, which permits unrestricted use, distribution, and reproduction in any medium, provided the original work is properly cited.

\begin{abstract}
A lab scale membrane bioreactor system was built to investigate the removal of Di-2-Ethyl Hexyl Phthalates (DEHP) in wastewater under variation of three runs: two hydraulic retention time (HRT) 24 and 36 hours in addition to two biomass: concentrated and light sludge. Solid phase extraction (SPE) followed by high performance liquid chromatography coupled with tandem mass spectrometry (HPLC-MS/MS) was applied to quantitatively identify DEHP in wastewater samples. Membrane bioreactor was built and operated to investigate DEHP removal. Higher HRT removed DEHP more efficiently than lower HRT. The concentrated MLSS could achieve higher removal efficiency than the lighter MLSS at the same HRT value. The performance of MBR in removing DEHP, TOC and COD from wastewater with a maximum removal efficiency were $29 \%, 85 \%$, and $98 \%$, respectively. Mass balance of DEHP in the system indicated that a majority was removed by adsorption process rather than filtration or microbiological process.
\end{abstract}

Keywords: DEHP; LC-MS/MS; Membrane Bioreactor (MBR); Solid Phase Extraction (SPE)

\section{Introduction}

Di-2-Ethyl Hexyl Phthalates (DEHP) is a manufactured chemical that is commonly added to plastics to make them flexible. This compound has been used in the production of many products such as polyvinyl chloride (PVC), paints, lubricants, pharmaceutics, cosmetics, insecticides, some toys, sheathing for wire and cable, medical tubing, and blood storage bags. The widespread applications of DEHP make it a ubiquitous environmental problem as it was detected in surface water, wastewater, seawater, sediment, soil even tap water throughout the world. It has been suggested in several human studies that DEHP can affect the developmental and reproductive systems (semen quality, genital development in boys, shortened pregnancy, and premature breast development in young girls) [1]. Numerous chronic effects such as hepatotoxicity, teratogenicity, carcinogenicity, adverse effects on male reproduction organs and endocrine disruption have been identified. Therefore, the US EPA has classified DEHP as a probable human carcinogen since 1987 [2]. In 2000, DEHP has been listed among the 33 hazardous substances to be

*Corresponding author. controlled in surface water by the European Community [3].

There are many methods cited in literature to remove DEHP including: activated sludge process [4], ozonation [5], oxidation by $\mathrm{UV} / \mathrm{H}_{2} \mathrm{O}_{2}$ photolysis [6], coupled biological and fenton treatment [7] as well as reverse osmosis and nanofiltration [8].

The concentration of DEHP reach $100 \mu \mathrm{g} / \mathrm{L}$ in the effluent [9] indicates that conventional activated sludge treatment system may have limited capability to remove this compound. Membrane bioreactors (MBRs) on other hand can produce high quality effluents suitable for reuse applications. The capability of MBRs to remove DEHP, however, has not been well examined.

Presently, MBR constitutes a promising technology in industrial and urban wastewater treatment. MBR is a combination of activated sludge and membrane separation processes into a single process where suspended solids and microorganisms are separated from the treated water by membrane filtration. The entire biomass is confined within the system, providing perfect control of the sludge age for the microorganisms in the reactor. As a result, it is feasible to work with high biomass concentrations and to control sludge retention time accurately, ob- 
taining a high quality permeate-effluent. High solids concentration inside the reactor might improve removal rates of lipophilic substances following a mechanism of sorption onto the sludge, and a longer SRT could favor the slowly growing bacteria, improving this way the biodiversity of microorganisms inside the MBR [10]. Thus, it is necessary to investigate the removal of DEHP by membrane bioreactor.

\section{Materials and Methods}

\subsection{Chemicals}

High purity DEHP ( $>99.7 \%$ purity) was purchased from Sigma Aldrich. Stock solution of DEHP was prepared in acetonitrile ( $>99.8 \%$ purity), which were from Merck (Germany).

\subsection{Sample Preparation and DEHP Analysis}

Samples were filtered by $1 \mu \mathrm{m}$ GF/B glass fiber filter. Solid phase extraction (SPE) followed by high performance liquid chromatography coupled with tandem mass spectrometry (HPLC-MS/MS) was applied to quantitatively identify DEHP in wastewater samples. DEHP was extracted from the filtrate by cartridge (Oasis HLB plus, $600 \mathrm{mg} / 6 \mathrm{~mL}$ ). Prior to extraction, the cartridges were placed on a vacuum manifold and conditioned sequentially with $5 \mathrm{~mL}$ of diethyl ether, $5 \mathrm{~mL}$ of methanol and 5 $\mathrm{mL}$ of deionized water at a flow rate of $1-2 \mathrm{~mL} / \mathrm{min}$. Then, samples were percolated through the cartridges at a flow rate of $1-2 \mathrm{~mL} / \mathrm{min}$. After that, the cartridges were cleaned with $3 \mathrm{~mL}$ of $10 \%(\mathrm{v} / \mathrm{v})$ methanol in water and dried under vacuum for 20 minutes. Cartridges were stored at $-4^{\circ} \mathrm{C}$ until elution and analysis. Then, $6 \mathrm{~mL}$ of a mixture of diethyl ether: methanol $(9: 1 ; \mathrm{v} / \mathrm{v})$ was percolated through cartridges to elute DEHP. After elution, the eluents were evaporated to dryness at $50^{\circ} \mathrm{C}$ under a stream of nitrogen. One milliliter of acetonitrile was added to dissolve the residues and resulting extracts were injected to LC-MS/MS system (Agilent 1200 SL highperformance liquid chromatograph (HPLC) interfaced with an Agilent 6400 Triple Quadrupole mass spectrometer (MS/MS)). The MS/MS was operated to detect liquid samples in electrospray ionization (ESI) negative mode. Analyte ion was monitored by using multiple reactions monitoring (MRM) mode. Ion selected was 149 $\mathrm{m} / \mathrm{z}$ and the retention time was $38 \mathrm{~min}$.

\subsection{Monitored Parameters}

Temperature, $\mathrm{pH}$, dissolved oxygen (DO), mixed liquor suspended solids (MLSS), mixed liquor volatile suspended solids (MLVSS), total organic carbon (TOC) and chemical oxygen demand (COD) were analyzed based on Standard Methods [11] and monitored in each run. The biomass variation; and COD, TOC and DEHP removal efficiency were observed.

\subsection{Acclimatization}

Activated sludge from a domestic wastewater treatment plant was used for microorganism seeding. The sludge was acclimated in 5 liter Sequencing Batch Reactor (SBR) by fill and draw operation for 2 cycles per day each consist of (approximately 2 min filling, $10 \mathrm{~h}$ aeration, $1-2 \mathrm{~h}$ settling and $15 \mathrm{~min}$ draw). A composition of synthetic wastewater used was glucose $(324 \mathrm{mg} / \mathrm{L})$, peptone $(192 \mathrm{mg} / \mathrm{L})$, meat extract $(132 \mathrm{mg} / \mathrm{L}), \mathrm{KH}_{2} \mathrm{PO}_{4}(28$ $\mathrm{mg} / \mathrm{L}), \mathrm{NaCl}(7 \mathrm{mg} / \mathrm{L})$, and $\mathrm{CaCl}_{2}$ (4 mg/L). In each cycle $2.5 \mathrm{~L}$ of synthetic wastewater is added and at the end of cycle $2.5 \mathrm{~L}$ of supernatant is removed. DEHP was added in incremental manner (start with $10 \mu \mathrm{g} / \mathrm{L}$ DEHP until reaching $100 \mu \mathrm{g} / \mathrm{L}$ ) after having desired MLSS. MLSS and MLVSS were monitored to see the variation of biomass in the entire acclimatization.

\subsection{Membrane Bioreactor Set up and Operation}

A lab scale membrane bioreactor was used in this study. The reactor made up of stainless steel tank with a working volume of $6 \mathrm{~L}$. An external ceramic membrane was connected to the bioreactor as shown in Figure 1. There are three tanks in the system: feed tank, bioreactor and effluent tank. The feed tank consists of synthetic wastewater, which was prepared every three days and it was mixed with submersible pump to make sure the homogeneously of synthetic wastewater. Automatic level controller opens the solenoid valve and maintains constant volume ( $=6$ Liter) in bioreactor tank. Bioreactor is supplied with air diffuser to maintain enough oxygen to bacteria in addition to provide adequate mixing in the tank. Permeate (effluent) was pumped out by suction with a circulation pump and speed controller to adjust the flow rate. A circulating pump with a flow rate of $2 \mathrm{~L} / \mathrm{min}$ pushed the wastewater through membrane unit where it re-circulated again to bioreactor and some being removed by suction pump to the effluent tank. Ceramic membrane

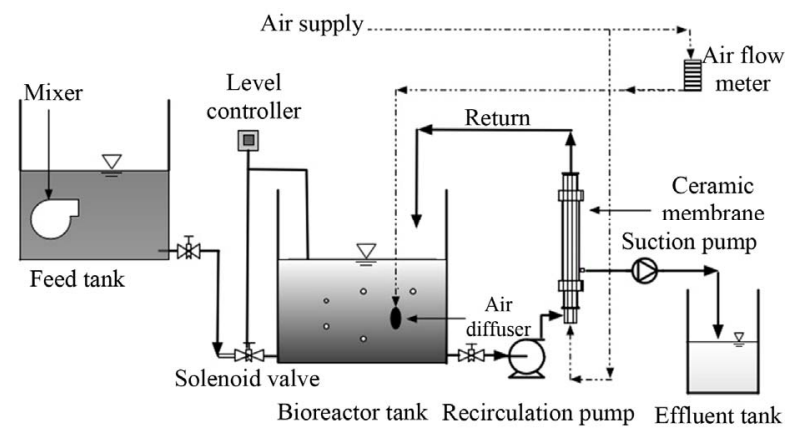

Figure 1. Schematic diagram of external membrane bioreactor experiment. 
of pore size $0.1 \mu \mathrm{m}$ and "inside-out" permeation direction was used for filtration and its specification is given on Table 1. Cleaning of membrane was carried out when the permeate flow is very low to meet the target HRT. At the early stages, the physical cleaning with water and air is enough while later stages chemical cleaning with $\mathrm{HNO}_{3}, \mathrm{NaOH}$ and $\mathrm{NaOCl}$ is required.

\subsection{Optimum Condition Studies on MBR}

The study was carried out to obtain the optimum condition for operating MBR for DEHP removal as well as maintaining the stability of the system. To obtain an appropriate MBR operation, different HRTs and biomass concentration were investigated with the influent concentration of DEHP range from 47 to $82 \mu \mathrm{g} / \mathrm{L}$. Three runs were carried out to investigate the performance of membrane bioreactor in removing DEHP. The details of operation days, biomass and HRT are shown in Table 2. The permeate flux was controlled by volumetric measurement of the effluent to maintain the desired HRT.

\subsection{Statistical Analysis of Results}

The results data of DEHP removal in three runs and mass balance were analyzed and graphically depicted with descriptive statistics so-called boxplot through their five-number summaries: the smallest observation (sample minimum), lower quartile (Q1), median (Q2), upper quartile (Q3), and largest observation (sample maximum). An additional character to represent the mean of the data was also presented.

Table 1. Specifications of the membrane.

\begin{tabular}{cc} 
Pore size & $0.1 \mu \mathrm{m}$ \\
Total area & $0.0575 \mathrm{~m}^{2}$ \\
Number of channels & 19 \\
Diameter of channel & $4 \mathrm{~mm}$ \\
Length of channel & $23.2 \mathrm{~cm}$ \\
Membrane material & Ceramic \\
Permeation direction & "Inside-out" \\
pH range & $0-14$ \\
Temperature limitation & up to $150^{\circ} \mathrm{C}$ \\
\hline
\end{tabular}

Table 2. Characteristics of the three runs of MBR.

\begin{tabular}{cccc}
\hline Run & $\begin{array}{c}\text { Operation Days } \\
\text { (From - To) }\end{array}$ & Biomass & HRT [h] \\
\hline 1 & $1-24$ & $\begin{array}{l}\text { Light sludge (initial MLSS }=3 \\
\text { g/L ) acclimatized for 100 days }\end{array}$ & 24 \\
2 & $25-43$ & $\begin{array}{l}\text { Concentrated sludge (initial MLSS } \\
=6 \text { g/L) acclimatized for 2 weeks }\end{array}$ & 24 \\
\hline
\end{tabular}

\section{Results and Discussion}

\subsection{Variation Performance of Each Run}

\subsubsection{MLSS and MLVSS Variation}

The variation of MLSS and MLVSS in the MBR is shown in Figure 2. Wide variation of MLSS and MLVSS were observed in the first week of operation due to unstable conditions in the MBR. Later on, the variation was small. MLVSS/MLSS ratio was very high (0.9) in Run1 and Run2 as the sludge was acclimatized for 100 day, while Run3 had low MLVSS/MLSS ratio (0.7) with high MLVSS and MLSS. High MLVSS in sludge means more microbes. More MLSS indicates more particulate matter in sludge. Therefore higher the MLVSS/MLSS ratio, better the performance of activated sludge process.

\subsubsection{COD Removal}

By looking at Figure 3, it can be noticed the COD removal efficiency in MBR was high with average removal efficiency at $77 \%$ (Min-Max $=60 \%-98 \%$ ). It can be seen that Run3 was the most efficient for removing COD in term of stability.

\subsection{Overall Removal of MBR}

As indicated in Figure 4, the system operated at higher HRT (36 h) removed DEHP more efficiently than lower

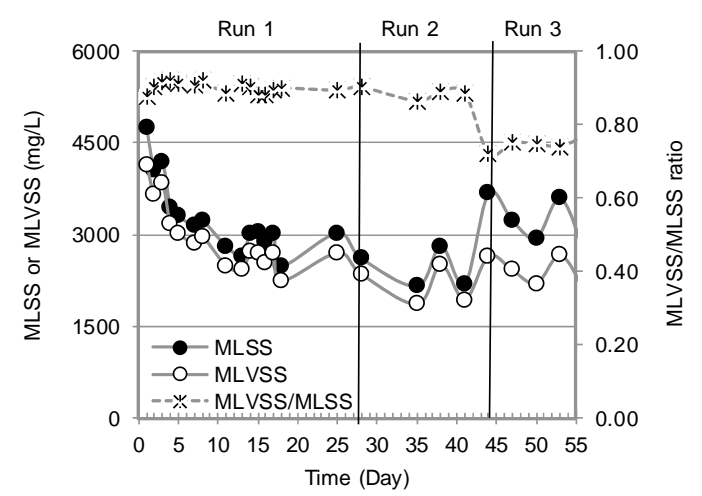

Figure 2. Biomass variation.

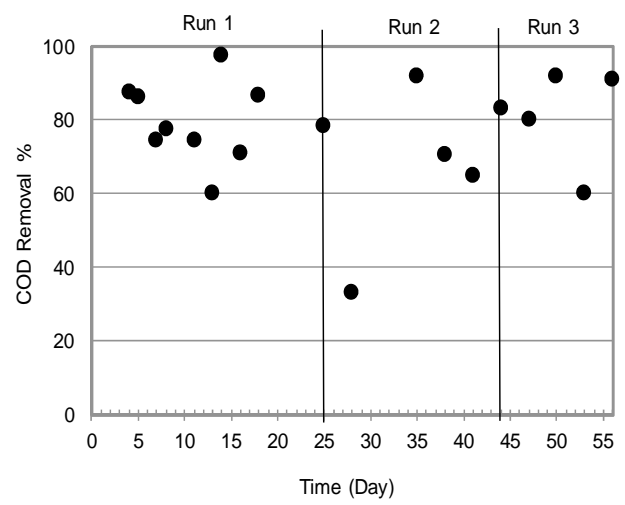

Figure 3. COD removal variation. 
HRT (24 h), which was compatible to what we expected as it gave much time for bacteria to have contact with sludge to remove DEHP. The concentrated sludge (Run3) could achieve higher removal efficiency than lighter sludge (Run1) at the same HRT value (24 h).

Although, the maximum DEHP removal in our system was $29 \%$, which is low in comparison to removal of other endocrine disrupting chemicals, removed by MBR, however, our research shows a higher removal than reported about DEHP removal in MBR system as indicated in Table 3.

\subsection{Mass Balance of DEHP and Removal Mechanism in MBR}

Figure 5 shows DEHP concentration variations in the influent, bioreactor and permeates of 3 runs. It was observed that the DEHP concentrations in the bioreactor and permeate (i.e. effluent) were very similar. Thus, it could be supposed that there is no retention by the membrane during filtration and could be assumed that DEHP retention by the membrane $(0.1 \mu \mathrm{m})$ was negligible.

As the filtration process was not the main process in removal of DEHP in MBR, either adsorption or biological process should be the important mechanism. Figure 6 presented the relation of MLSS, MLVSS and DEHP removal efficiency of Run 1 and 3 (same HRT). It could be observed that DEHP removal increased when MLSS increased while MLVSS decreased, suggesting the adsorption process played important role of DEHP removal [14] in MBR.

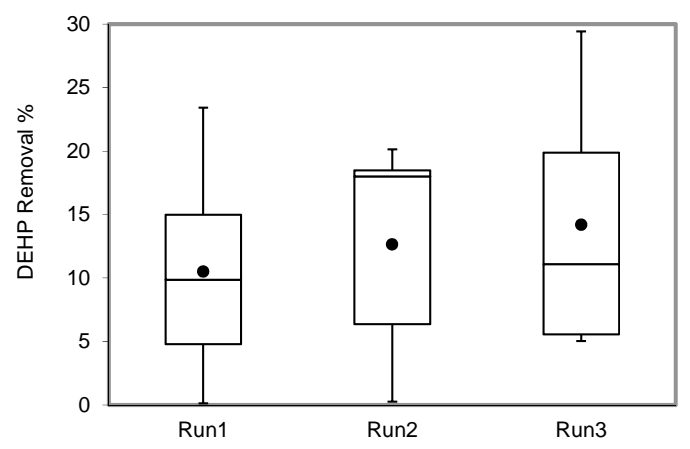

Figure 4. DEHP removal in three runs.

Table 3. Removal of DEHP in membrane bioreactor.

\begin{tabular}{cccc}
\hline $\begin{array}{c}\text { Type of } \\
\text { wastewater }\end{array}$ & $\begin{array}{c}\text { Influent DEHP } \\
\text { concentration }\end{array}$ & HRT [h] & $\begin{array}{c}\text { \% Removal } \\
\text { (Max.) }\end{array}$ \\
\hline Industrial $^{1}$ & $65.5 \mu \mathrm{g} / \mathrm{L}$ & $8 \& 16$ & $10.2 \%$ \\
Domestic $^{2}$ & $\approx 8 \mu \mathrm{g} / \mathrm{L}$ & - & $25 \%$ \\
Synthetic $^{3}$ & $40-82 \mu \mathrm{g} / \mathrm{L}$ & $24 \& 36$ & $29 \%$ \\
\hline
\end{tabular}

${ }^{1}[12],{ }^{2}[13],{ }^{3}$ This study.

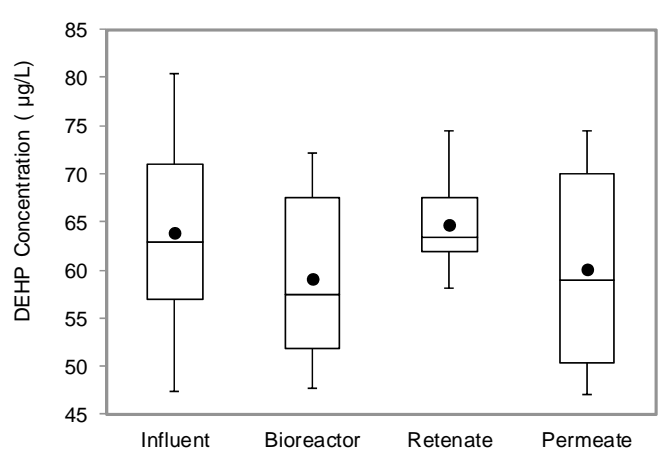

Figure 5. DEHP mass balance.

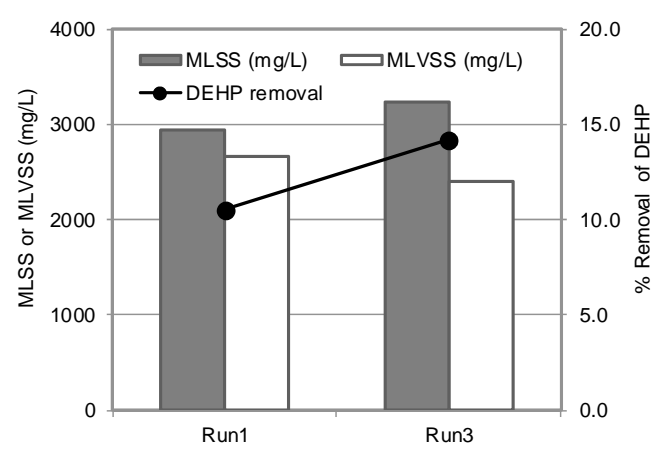

Figure 6. MLSS, MLVSS and DEHP removal.

\section{Conclusion}

A maximum DEHP removal was $29 \%$ at HRT $=36 \mathrm{~h}$ with the performance of MBR in removing COD at a maximum removal efficiency of $98 \%$. HRT at $36 \mathrm{~h}$ could remove DEHP more efficiently than lower HRT at $24 \mathrm{~h}$. The concentrated MLSS could achieve higher removal ef- ficiency than the lighter at the same HRT. DEHP removal increased when MLSS increased while MLVSS decreased, suggesting that adsorption mechanism played the important role of DEHP removal in MBR.

\section{Acknowledgements}

This research was financially supported by Faculty of Engineering, Mahidol University. A special thanks to Prof. C. Visvanathan from AIT for his generous support in providing membrane module and other equipment.

\section{REFERENCES}

[1] Agency for Toxic Substances and Disease Registry (ATSDR), "Toxicological Profile for Di(2-Ethylhexyl)phthalate (DEHP)," US Department of Health and Human Services, Public Health Service, Atlanta, 2002.

[2] H. Chan, C. Chan, P. Ang and P. Wong, "Integrated Biosorption and Photo Catalytic Oxidation Treatment of Di(2-Ethylhexyl) Phthalate," Journal of Applied Phycology, Vol. 19, No. 6, 2007, pp. 745-753. doi:10.1007/s10811-007-9218-Z 
[3] C. Dargnat, M. Teil, M. Chevreuil and M. Blanchard, "Phthalate Removal throughout Wastewater Treatment Plant: Case Study of Marne Aval station (France)," Science of The Total Environment, Vol. 407, No. 4, 2009, pp. 1235-1244. doi:10.1016/i.scitotenv.2008.10.027

[4] S. K. Marttinen, R. H. Kettunen, K. M. Sormunen and J. A. Rintala, "Removal of Bis (2-Ethylhexyl) Phthalate at a Sewage Treatment Plant," Water Research, Vol. 37, No. 6, 2003, pp. 1385-1393. doi:10.1016/S0043-1354(02)00486-4

[5] M. Khan and J. Jung, "Ozonation Catalyzed by Homogeneous and Heterogeneous Catalysts for Degradation of DEHP in Aqueous Phase," Chemosphere, Vol. 72, No. 4, 2008, pp. 690-696. doi:10.1016/j.chemosphere.2008.02.037

[6] C. Chen, "The Oxidation of Di-(2-Ethylhexyl) Phthalate (DEHP) in Aqueous Solution by $\mathrm{UV} / \mathrm{H}_{2} \mathrm{O}_{2}$ Photolysis," Water, Air, and Soil Pollution, Vol. 209, No. 1-4, 2009, pp. 411-417. doi:10.1007/s11270-009-0209-3

[7] C. Chen, P. Wu and Y. Chung, "Coupled Biological and Photo-Fenton Pretreatment System for the Removal of Di-(2-Ethylhexyl) Phthalate (DEHP) from Water," Bioresource Technology, Vol. 100, No. 19, 2009, pp. 45314534. doi:10.1016/j.biortech.2009.04.020

[8] M. Bodzek, M. Dudziak and K. Luks-Betlej, "Application of Membrane Techniques to Water Purification. Removal of Phthalates," Desalination, Vol. 162, 2004, pp. 121-128. doi:10.1016/S0011-9164(04)00035-9

[9] J. Sanchez, J. Bonet, G. Velasco and S. Lacorte, "Determination and Occurrence of Phthalates, Alkylphenols, Bisphenol A, PBDEs, PCBs and PAHs in an Industrial
Sewage Grid Discharging to a Municipal Wastewater Treatment Plant," Science of The Total Environment, Vol. 407, No. 13, 2009, pp. 4157-4167. doi:10.1016/j.scitotenv.2009.03.016

[10] R. Reif, S. Suarez, F. Omil and J. Lema, "Fate of Pharmaceuticals and Cosmetic Ingredients during the Operation of a MBR Treating Sewage," Desalination, Vol. 221, No. 1-3, 2008, pp. 511-517. doi:10.1016/j.desal.2007.01.111

[11] APHA, AWWA, and WEF, "Standard Methods for the Examination of Water and Wastewater (20th Edition)," American Public Health Association, American Water Works Association and Water Environment Federation, Washington DC,1998.

[12] A. Llop, F. Borrull and E. Pocurull, "Comparison of the Removal of Phthalates and Other Organic Pollutants from Industrial Wastewaters in Membrane Bioreactor and Conventional Activated Sludge Treatment Plants," Water Science and Technology, Vol. 60, No. 9, 2009, pp. 24252437. doi:10.2166/wst.2009.314

[13] H. Wenzel, F. Larsen, J. Kaas, L. Hoibye and B. Jacobsen, "Weighing Environmental Advantages and Disadvantages of Advanced Wastewater Treatment of Micro-Pollutants Using Environmental Life Cycle Assessment," Water Science and Technology, Vol. 57, No. 1, 2008, pp. 27-32. doi:10.2166/wst.2008.819

[14] S. A. Sakiti, S. K. Boontanon and N. Boontanon, "Sorption of Di-2-Ethyl Hexyl Phthalate (DEHP) by Activated Sludge," Proceeding of the $20^{\text {th }}$ National Grad Research Conference, Mahidol University, Salaya, 2011, pp. 1-6. 